\title{
Protein degradation by ubiquitin-proteasome system in formation and labilization of contextual conditioning memory
}

\author{
María Sol Fustiñana, ${ }^{1,2}$ Verónica de la Fuente, ${ }^{1}$ Noel Federman, ${ }^{1}$ Ramiro Freudenthal, ${ }^{1}$ \\ and Arturo Romano ${ }^{1}$ \\ ${ }^{1}$ Laboratorio de Neurobiología de la Memoria, Departamento de Fisiología, Biología Molecular y Celular, Facultad de Ciencias \\ Exactas y Naturales, Universidad de Buenos Aires, IFIByNE, CONICET, Ciudad Universitaria, 1428EHA, Buenos Aires, Argentina
}

\begin{abstract}
The ubiquitin-proteasome system (UPS) of protein degradation has been evaluated in different forms of neural plasticity and memory. The role of UPS in such processes is controversial. Several results support the idea that the activation of this system in memory consolidation is necessary to overcome negative constrains for plasticity. In this case, the inhibition of the UPS during consolidation impairs memory. Similar results were reported for memory reconsolidation. However, in other cases, the inhibition of UPS had no effect on memory consolidation and reconsolidation but impedes the amnesic action of protein synthesis inhibition after retrieval. The last finding suggests a specific action of the UPS inhibitor on memory labilization. However, another interpretation is possible in terms of the synthesis/degradation balance of positive and negative elements in neural plasticity, as was found in the case of long-term potentiation. To evaluate these alternative interpretations, other reconsolidation-interfering drugs than translation inhibitors should be tested. Here we analyzed initially the UPS inhibitor effect in contextual conditioning in crabs. We found that UPS inhibition during consolidation impaired long-term memory. In contrast, UPS inhibition did not affect memory reconsolidation after contextual retrieval but, in fact, impeded memory labilization, blocking the action of drugs that does not affect directly the protein synthesis. To extend these finding to vertebrates, we performed similar experiments in contextual fear memory in mice. We found that the UPS inhibitor in hippocampus affected memory consolidation and blocked memory labilization after retrieval. These findings exclude alternative interpretations to the requirement of UPS in memory labilization and give evidence of this mechanism in both vertebrates and invertebrates.
\end{abstract}

The ubiquitin-proteasome system (UPS) has initially been postulated as a necessary mechanism for degradation of neural plasticity inhibitors. In particular, the ubiquitin hydroxylase expression was related with the degradation of the cAMP-dependent protein kinase (PKA) regulatory subunit (R) in Aplysia sensory-motor synapses plasticity. This $\mathrm{R}$ subunit is a pseudosubstrate that inhibits the catalytic (C) subunit activity. In that way, the degradation of the $\mathrm{R}$ subunit mediates long-term activation of the $\mathrm{C}$ subunit (Chain et al. 1999). The UPS is also critical for memory consolidation in vertebrates. In spatial memory in mice, protein degradation by the UPS is required in hippocampus during consolidation (Artinian et al. 2008). In rats, bilateral injection of the proteasome inhibitor lactacystin into the CA1 region of the hippocampus blocked long-term memory formation in a one-trial inhibitory avoidance task. Consistent with the need for UPS-mediated degradation, levels of ubiquitinated synaptic proteins increased in the hippocampus following training (Lopez-Salon et al. 2001). In search of target proteins that are degraded during consolidation, the authors found no degradation of the PKA R subunit but of the inhibitor kappa B (IkB). IkB is the inhibitory regulator of the nuclear factor kappa B (NF-kB), a transcription factor which is involved in synaptogenesis (Boersma et al. 2011) and that plays a key role in memory and neural plasticity (Meffert and Baltimore 2005; Romano et al. 2006a). Similar mechanisms govern memory

\footnotetext{
${ }^{2}$ Present address: Friedrich Miescher Institute for Biomedical Research, 4058 Basel, Switzerland

Corresponding author: aromano@fbmc.fcen.uba.ar

Article is online at http://www.learnmem.org/cgi/doi/10.1101/Im.035998.114.
}

consolidation in invertebrates, for instance the context-signal memory in crabs, where the inhibition of NF-кB was associated with the amnesic effect of UPS inhibition (Merlo and Romano 2007).

Modification of neuronal connections by activity is essential for learning and memory functions of the brain. Long-term depression (LTD) as well as long-term potentiation (LTP), two opposing forms of neural plasticity associated with long-term memory in glutamatergic paths, can be blocked by UPS inhibition (Colledge et al. 2003; Ehlers 2003; Hou et al. 2006; Karpova et al. 2006).

A classical tenet in the field is that during consolidation, memory passes from a labile phase into a stable and enduring state (Müller and Pilzecker 1900). However, numerous studies have showed that once a memory is consolidated, it can be labilized and become sensitive again to amnesic agents if a reminder is presented. The reactivation of the original memory by the reminder and the subsequent labilization triggers a re-stabilization process similar, but not equal, to that observed during consolidation at both the systemic and cellular level (Misanin et al. 1968; Mactutus et al. 1979; Sekiguchi et al. 1997; Nader et al. 2000; Sara 2000; Kida et al. 2002; Pedreira et al. 2002; Boccia et al.

C 2014 Sol Fustiñana et al. This article is distributed exclusively by Cold Spring Harbor Laboratory Press for the first 12 months after the full-issue publication date (see http://learnmem.cshlp.org/site/misc/terms.xhtml). After 12 months, it is available under a Creative Commons License (AttributionNonCommercial 4.0 International), as described at http://creativecommons. org/licenses/by-nc/4.0/. 
2007). This phenomenon, called reconsolidation, is present in different types of learning and in diverse phylogenetic lines such as mollusks, crustaceans, birds, rodents, and humans (Dudai 2006). In the case of associative learning, memory is usually reactivated by the presentation of the conditioned stimulus (CS) without the unconditioned stimulus (US). In associative contextual models, the CS presentation consists in the re-exposure of the animal to the training context. Memory reactivation by the CS can trigger two apparently competing mechanisms depending on the duration of the re-exposure: reconsolidation and extinction, as initially characterized in crabs (Pedreira and Maldonado 2003). The role of the UPS in reconsolidation is controversial. In spatial memory in mice, the inhibition of proteasome-dependent protein degradation in hippocampus during reconsolidation impaired subsequent long-term memory (Artinian et al. 2008). In contrast, no effect was observed for fear conditioning upon inhibition in either hippocampus (Lee et al. 2008) or amygdala (Jarome et al. 2011), or for cocaine-induced conditioned place preference in the nucleus accumbens (Ren et al. 2013). Similar results were reported in sensitization and facilitation in Aplysia (Lee et al. 2012). Interestingly however, inhibition of proteasome-dependent protein degradation blocked the amnesic action of protein synthesis inhibitors (Lee et al. 2008, 2012; Jarome et al. 2011; Ren et al. 2013). These findings were interpreted as a specific action of the UPS inhibitor on memory labilization, suggesting that the translation blocker was no longer amnesic because memory could not become labile after retrieval. However, another interpretation is possible in terms of the balance between synthesis and degradation of positive and negative elements in neural plasticity, as was found in the case of LTP (Fonseca et al. 2006). In this work, the pharmacological inhibition of either UPS or protein synthesis disrupted the expression of the late phase of LTP. However, when protein degradation and protein synthesis were inhibited at the same time, LTP was no affected. These findings suggest that LTP, and perhaps other forms of plasticity and memory, may require the combined action of degradation and synthesis of plasticity proteins. It is therefore conceivable that the balance of degradation and synthesis of some key proteins could be a crucial factor regulating memory re-stabilization in reconsolidation. The results obtained in fear conditioning, conditioned place preference and in Aplysia sensitization, in which the simultaneous inhibition of both UPS and translation caused no effect in reconsolidation could also be attributable to the interpretation of a balance between synthesis and degradation. In these cases, protein degradation may not be critical for reconsolidation but when protein degradation is inhibited, new protein synthesis is no longer required because the preexistent proteins are enough to sustain the plasticity process.

To evaluate these alternative interpretations other reconsolidation-interfering drugs than translation inhibitors should be tested. If UPS inhibitors are able to block memory impairment or enhancement induced by such drugs, then the role of protein degradation in memory labilization could be confirmed beyond its effect on the synthesis/degradation balance. Here we used a contextual conditioning task in crabs to analyze the effect of UPS inhibition in combination with the memory-disrupting drugs MK801 and sulfasalazine, and with the memory-enhancing drug bicuculline. To extend these findings to vertebrates, we performed similar experiments with sulfasalazine as memory-disrupting drug and the calcineurin $(\mathrm{CaN})$ inhibitor FK506 as memory-enhancing drug in another example of contextual conditioning, the contextual fear memory in mice.
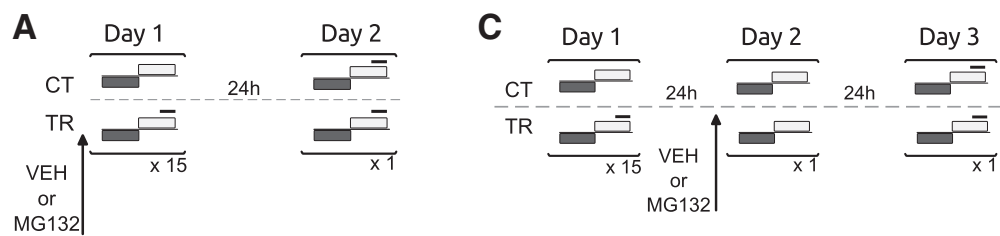

B

Day 2 - Test

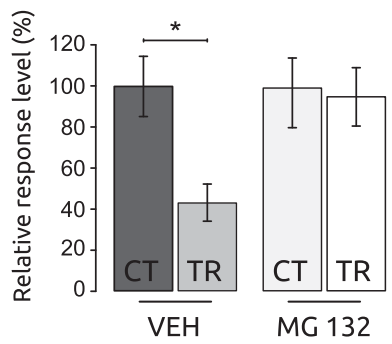

D

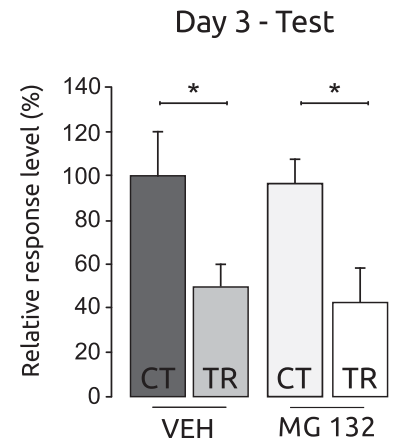

Figure 1. Proteasome inhibition impairs memory consolidation but has no effect on memory reconsolidation in a contextual Pavlovian conditioning (CPC) protocol. $(A)$ Experimental protocol. On Day 1, one pair of control animals that did not receive the danger stimulus (CT) and animals that received the danger stimulus (TR) was injected with vehicle (VEH) and the other pair was injected with MG132 (2.38 $\mu \mathrm{g} /$ animal). The injections were performed immediately before the training session. On Day 2 animals received the testing session. Gray horizontal bars indicate light from below, white horizontal bars indicate light from above, and solid black lines indicate the visual danger stimulus presentation. (B) Testing session. Mean response \pm SEM on Day 2 normalized to the VEH-CT group; $\left({ }^{*}\right) P<0.05, n=30$, per group. (C) Experimental protocol. On Day 1, the protocol was as in A. On Day 2, animals were reexposed to the training context. One pair of CT and TR was injected with VEH and the other pair was injected with MG132. The injections were performed 20 min before the reexposure session. On Day 3, animals received the testing session. (D) Testing session. Mean response \pm SEM on Day 3 normalized to the VEH-CT group; $\left(^{*}\right) P<0.05, n=40$, per group.

\section{Results}

\section{Inhibition of the UPS during consolidation impairs long-term memory in crab contextual conditioning}

As outlined above, the results available in the literature about the action of UPS inhibition during memory consolidation are contradictory, with most studies reporting memory impairment, whereas in two cases no effect was found (Lee et al. 2008, 2012). To further explore this issue, we initially studied the effect of UPS inhibition on long-term memory in contextual conditioning of the crab Chasmagnathus. In this task, a context (conditioned stimulus, CS) was presented with a cofinishing unconditioned stimulus (US), a visual danger stimulus (Fustiñana et al. 2013). We administered the proteasome inhibitor MG132 at a 2.38 $\mu \mathrm{g} /$ animal dose or dimethyl sulfoxide as vehicle (VEH) systemically before training (15-trials) to either trained animals (TR group) or control animals that did not receive the danger stimulus (CT group). The experiment thus had four groups: CT-VEH, CT-MG132, TR-VEH, and TR-MG132. Twenty-four hours later we tested these groups using a single CS-US presentation (Fig. 1A). These 
data show that the TR group injected with VEH had significantly lower levels of escape responses compared with the CT-VEH group. In contrast, the TR-MG132 level of response was similar to the CT-MG132 group, indicating that the drug caused a memory impairment $\left(F_{(3,116)}=3.35 ; P<0.05\right.$; CT-VEH vs. TR-VEH: $P<0.05$ and CT-MG132 vs. TR-MG132: $P$ : NS) (Fig. 1B). Together, these results suggest that proteasome inhibition disrupts consolidation of contextual memory in the crab model.

\section{Inhibition of the UPS during reconsolidation does not impair long-term memory}

In the following experiment we evaluated the effect of a UPS inhibitor during memory reconsolidation. In contextual conditioning of Chasmagnathus, memory retrieval is induced by a brief re-exposure of the animals to the CS without US presentation (Fustiñana et al. 2013). The retrieval session consisted of $27 \mathrm{sec}$ of re-exposure to the CS with $5 \mathrm{~min}$ of total re-exposure to the experimental device. Under these conditions, memory is labilized and the reconsolidation process is induced (Fustiñana et al. 2013). We trained two pairs of TR and CT groups, and $24 \mathrm{~h}$ later one CT-TR pair was injected with MG132 at the same dose used in the previous experiment and the other CT-TR pair was injected with vehicle (four groups: CT-VEH, TR-VEH, CT-MG132, and TR-MG132). Twenty minutes after injection all crabs received a retrieval session and $24 \mathrm{~h}$ later they were tested with one CS-US presentation (Fig. 1C). We observed a significant difference between the two CT groups and their matched TR groups $\left(F_{(3,156)}=4.13\right.$; $P<0.05$; CT-VEH vs. TR-VEH: $P<0.05$ and CT-MG132 vs. TR-MG132: $P<0.05$ ) (Fig. 1D). These results indicated that the MG132 administration, at the same dose which caused memory impairment during consolidation in the previous experiment, had no effect on memory reconsolidation.

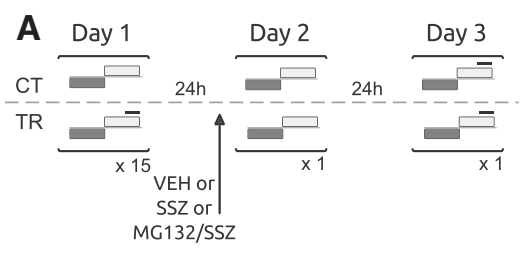

B

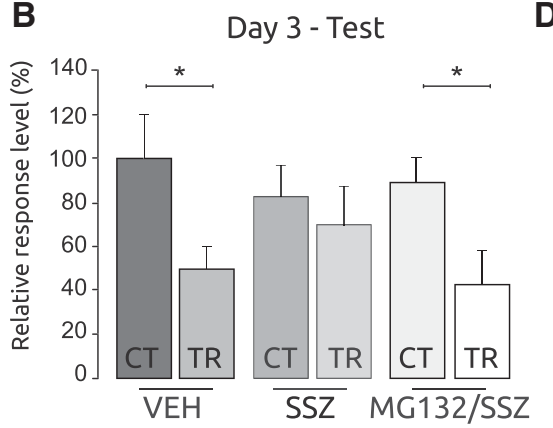

C

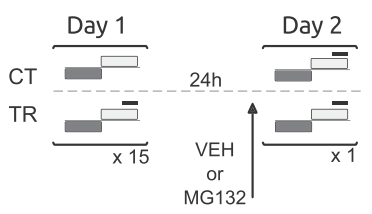

D

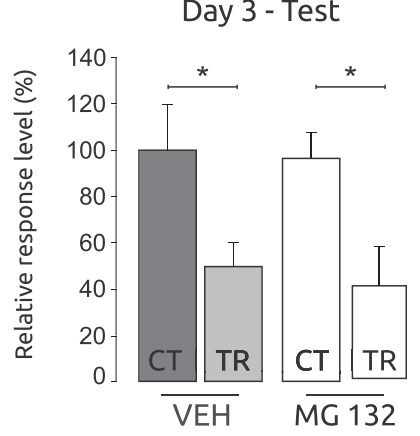

Figure 2. Inhibition of the proteasome impairs the amnesic effect of the SSZ over the reconsolidation of memory in a CPC protocol. However, proteasome inhibition does not impair memory recall. $(A)$ Experimental protocol. On Day 1, the training session was performed. Three groups of control animals did not receive the danger stimulus (CT) and three groups of trained animals received the danger stimulus (TR). On Day 2, each pair of CT/TR group was injected before re-exposure to the training device. The drugs administered were VEH or SSZ (20 $\mathrm{g}$ /animal) or a cocktail of SSZ and MG132. On Day 3, the testing session was performed. Gray horizontal bars indicate light from below, white horizontal bars indicate light from above, and solid black lines indicate the visual danger stimulus presentation. (B) Testing session. Mean response \pm SEM on Day 3 normalized to the VEH-CT group; $\left(^{*}\right) P<0.05, n=30$, per group. (C) Experimental protocol. On Day 1 the training was performed as before. On Day 2 the animals were injected with VEH or MG132 10 min before the testing session. (D) Testing session. Mean response \pm SEM on Day 2 normalized to the VEH-CT group, $\left({ }^{*}\right) P<0.05, n=30$, per group.

\section{Inhibition of the UPS during reconsolidation blocks}

Inhibition of the UPS has been reported to rescue memory impairment induced by inhibition of translation during reconsolidation (Lee et al. 2008, 2012; Jarome et al. 2011; Ren et al. 2013; see hibitors interfering a different molecular mechanism, we focused our attention on the transcription factor nuclear factor kappa $B$ $(\mathrm{NF}-\kappa \mathrm{B})$. The activation and translocation to the nucleus of $\mathrm{NF}-\kappa \mathrm{B}$ is an important regulatory mechanism of gene expression during memory formation in both vertebrates and invertebrates for review, see Meffert and Baltimore 2005; Romano et al. 2009). This transcription factor is also involved Lubin and Sweatt 2007; de la Fuente et al. 2011; Si et al. 2012). A key mechanism in the NF-кB pathway is the activation of IkB kinase (IKK). Upon its activation, IKK phosphorylates IkB, a regulatochibits NF- $\mathrm{B}$. Once phosphorylated, IkB is et al. 1996). Sulfasalazine is a potent and specific inhibitor of IKK (Wahl et al. 1998) that interferes with the ATP-binding site of the kinase (Weber et al. 2000; Merlo et al. 2002). This drug was xtensively used for memory disruption in both consolidation (Merlo et al. 2002, 2005; Freudenthal et al. 2005; Boccia et al. 2007; Lubin and Sweatt 2007; Si et al. 2012). memory specifically when it was reactivated by presentation 2013). To test whether the proteasome inhibitor MG132 is able to block this memory impairment of sulfasalazine in reconsolidation, we trained three matched pairs of TR and CT groups. Twenty-four hours later one CT-TR pair was injected with sulfasalazine at a $20 \mu \mathrm{g} /$ animal dose, one pair was injected with a cocktail of MG132 and sulfasalazine and the other CT-TR pair was injected with vehicle, yielding six groups: CT-VEH, TR-VEH, CT-SSZ, TR-SSZ, CT-MG132/SSZ, and TRMG132/SSZ. Twenty minutes after injection all crabs received a retrieval session. These groups were tested $24 \mathrm{~h}$ after reexposure (Fig. 2A). Consistent with previous results, the CT-SSZ versus TR-SSZ pair showed no significant differences in planed comparisons. In contrast, the other pair comparisons displayed a significantly lower level of response for TR groups versus CT groups (Fig. 2B; $F_{(5,174)}=3.08 ; \quad P<0.05 ; \quad$ CT-VEH vs. TR-VEH: $P<0.05$, CT-SSZ vs. TR-SSZ: $P$ : NS and CT-MG132/SSZ vs. TR-MG132/ SSZ: $P<0.05)$. These results are in agreement with previous finding in mouse and Aplysia, which indicated that the inhibition of UPS blocked the action of amnesic drugs.

\section{Inhibition of the UPS does not interfere with memory retrieval}

The results of the previous experiment suggest that MG132 is able to block the effect of IKK/NF-кB pathway inhibition, suggesting that UPS inhibition prevents labilization of the memory. However, 
A

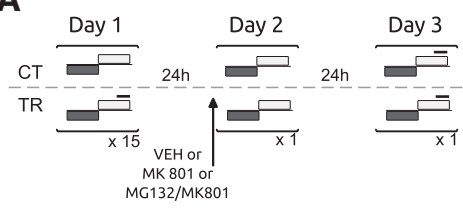

B

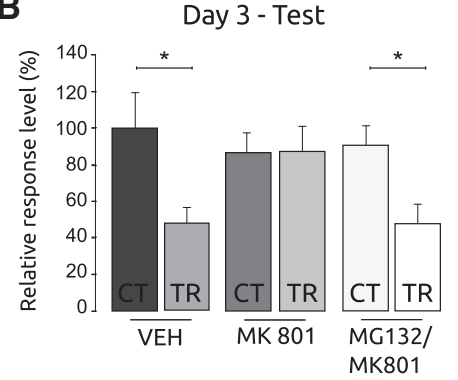

C

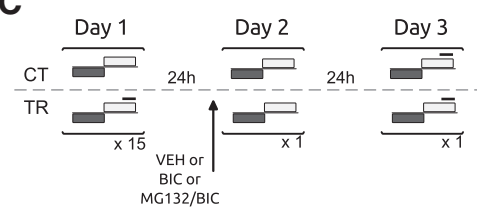

D

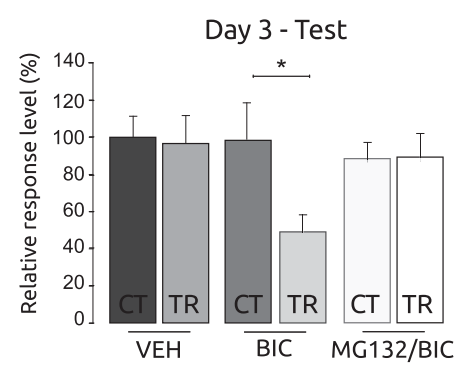

Figure 3. Proteasome inhibition impairs the amnesic effect of the MK801 and the enhancement of bicuculline in the reconsolidation of the memory. $(A)$ Experimental protocol. On Day 1, the training session was performed. Three groups of control animals did not receive the danger stimulus (CT) and three groups of animals received the danger stimulus (TR). On Day 2, each pair of the CT/TR group was injected before re-exposure to the training device. The drugs administered were VEH or MK801 $(10 \mu \mathrm{g} /$ animal) or a cocktail of MK801 and MG132. On Day 3 the testing session was performed. Gray horizontal bars indicate light from below, white horizontal bars indicate light from above, and solid black lines indicate the visual danger stimulus presentation. (B) Testing session. Mean response \pm SEM on Day 3 normalized to the VEH-CT group; $\left({ }^{*}\right) P<0.05, n=30$, per group. (C) Experimental protocol. On Day 1, a weak training session was performed. Three groups of control animals did not received the danger stimulus (CT) and three groups of animals received only four trials (TR). On Day 2, each pair of CT/TR group was injected before re-exposure to the training device. The drugs administered were VEH, BIC (46 $\mu \mathrm{g} /$ animal) or a cocktail of BIC and MG132.On Day 3 the testing session was performed. (D) Testing session. Mean response \pm SEM on Day 3 normalized to the VEH-CT group; $\left({ }^{*}\right) P<0.05, n=30$, per group.

alternatively it is conceivable that MG132 interferes with memory retrieval, a process that is required for memory labilization. To evaluate this possibility of retrieval interference, we performed an experiment with two pairs of CT-TR groups that were injected with MG132 or VEH 20 min before the memory test, $24 \mathrm{~h}$ after training (Fig. 2C). The results indicated significant differences in CT versus TR comparisons for both pairs, suggesting that MG132 did not interfered with memory retrieval (Fig. 2D; $F_{(3,116)}=3.81 ; P<0.05$; CT-VEH vs. TR-VEH: $P<0.05$ and CT-MG132 vs. TR-MG132: $P<0.05)$.

\section{Inhibition of the UPS blocks the action of MK801 and bicuculline on memory}

Having established that UPS inhibition can block the effect of sulfasalazine on reconsolidation, we asked whether similar effects can be observed for drugs affecting reconsolidation by different mechanisms. The first experiment was conducted using MK801, a non-competitive antagonist of the $\mathrm{N}$-methyl D-aspartate glutamate receptors (NMDAR). This drug has been widely used as an amnesic agent in several memory tasks in different species (Morris et al. 1986; Tan et al. 1989; Miserendino et al. 1990; Lin and Glanzman 1994; Rickard et al. 1994; Weldon et al. 1997; Gutiérrez et al. 1999; Roberts and Glanzman 2003; Si et al. 2004; Xia et al. 2005; Wu et al. 2007; Kano et al. 2008; Müssig et al. 2010; Rosenegger and Lukowiak 2010; Amano and Maruyama 2011). Moreover, MK801 caused amnesic effects in consolidation (Troncoso and Maldonado 2002), reconsolidation and extinction (Pérez-Cuesta and Maldonado 2009) in Chasmagnathus, consistent with the presence of NMDAR in the crab CNS (Hepp et al. 2013). During the training session on Day 1, we established three pairs of
CT-TR groups. On Day 2, one matched pair of groups was injected with vehicle, another with MK801 at a $10 \mu \mathrm{g} / \mathrm{animal}$ dose, and the last pair with an MG132/ MK801 cocktail (CT-VEH, TR-VEH, CTMK801, TR-MK801, CT-MG132/MK801 and TR-MG132/MK801). Twenty minutes after injection all crabs received a retrieval session. On Day 3, these groups were tested (Fig. 3A). A significant difference between CT and TR groups was observed for the VEH pair, indicating memory retention on Day 3. In contrast, the MK801 pair did not show statistical difference, due to the high level of response in both groups. This is indicative of an amnesic effect of the drug. Conversely, the MG132/MK801 cocktail pair showed a significant difference $\left(F_{(5,174)}=3.70 ; \quad P<0.05 ;\right.$ CT-VEH vs. TR-VEH: $P<0.05$, CT-MK vs. TR-MK: $P: \quad$ NS and CT-MG132/MK vs. TRMG132/MK: $P<0.05$ ) (Fig. 3B), indicating memory retention and suggesting that MG132 blocked the amnesic effect of MK801 during reconsolidation.

Labilization and reconsolidation open a time window not only for disruption, but also for enhancement of the memory trace (Delorenzi and Maldonado 1999; Carbo Tano et al. 2009). In the following experiment we evaluated whether MG132 is able to impede memory enhancement induced by bicuculline, a competitive antagonist of $\gamma$ aminobutyric acid type $A$ receptor $\left(G_{A B A} R\right)$. Bicuculline has been found to induce memory enhancement in different species and types of learning (Chapouthiers and Venault 2002). In particular, bicuculline caused enhancement of consolidation and reconsolidation in the crab (Carbo Tano et al. 2009, Fustiñana et al. 2013). During training session on Day 1, animals received a weak training protocol of four trials, which does not lead to memory retention. We established three pairs of CT-TR groups. On Day 2, one pair of groups was injected with vehicle, other with bicuculline at a $46 \mu \mathrm{g} /$ animal dose and the last pair injected with the MG132/bicuculline cocktail (CT-VEH, TRVEH, CT-BIC, TR-BIC, CT-MG132/BIC, and TR-MG132/BIC). Twenty minutes after injection, all crabs received a retrieval session. On Day 3, these groups were tested (Fig. 3C). As expected due to the weak training used, no difference was found between CT-VEH and TR-VEH. In contrast, TR-BIC showed a significantly lower level of response than CT-BIC, indicating memory retention. Thus, bicuculline injection induced memory enhancement. Conversely, no difference was found between CT and TR groups injected with MG132/BIC cocktail (Fig. 3D) $\left(F_{(5,174)}=\right.$ 2.29; $P<0.05$; CT-VEH vs. TR-VEH: $P$ : NS, CT-BIC vs. TRBIC: $P<0.05$ and CT-MG132/BIC vs. TR-MG132/BIC: $P$ : NS). This result suggests that MG132 was able to impede the enhancement effect of bicuculline.

\section{Inhibition of the UPS in mouse hippocampus during reconsolidation blocks the amnesic effect of sulfasalazine on fear memory}

All experiments presented so far support the interpretation that UPS inhibition in the crab impedes the action of other drugs 
on memory reconsolidation by means of blocking the labilization process. To extend these finding to vertebrates, we performed similar experiments using contextual fear conditioning in mice. In this task, mice receive three footshocks in a particular context. Memory labilization and reconsolidation is induced by a re-exposure $(5 \mathrm{~min})$ to the training context without footshock $1 \mathrm{~d}$ after training (de la Fuente et al. 2011). After the re-exposure session, four groups of animals were bilaterally infused into hippocampus with either vehicle (VEH group), $0.5 \mu \mathrm{g} /$ hemisphere of sulfasalazine (SSZ group, $0.05 \mu \mathrm{g} /$ hemisphere of MG132 (MG132 group), or the sufasalazine/MG132 cocktail (SSZ/MG132 group). On Day 2 all groups of animals showed high percentage of freezing without difference between them, revealing retention of memory $\left(F_{(3,36)}=1.99, P=\right.$ 0.13 ; VEH vs. SSZ: $P$ : NS; VEH vs. MG132: P: NS; VEH vs. MG132/SSZ: P: NS; SSZ vs. MG132: $P$ : NS; SSZ vs. MG132/SSZ: P: NS; MG132 vs. MG132/ SSZ: $P$ : NS; data not shown). On Day 3 , mice were tested by a second re-exposure of 5 min (Fig. 4A). During testing, the percentage of freezing was determined (Fig. 4B). As expected, the VEH group showed a high level of freezing, above $40 \%$, and the SSZ group showed a significantly lower level of freezing $\left(F_{(3,36)}=6.31, P<0.05\right.$; VEH vs. SSZ: $P<0.05$; SSZ vs. MG132: $P<0.05$; SSZ vs. MG132/SSZ: $P<0.05)$. These results indicate that inhibition of the IKK/NF-кB pathway during memory reconsolidation causes memory impairment. Conversely, the MG132 group showed high levels of freezing that were not significantly different to the VEH group levels, but significantly higher than the SSZ group, suggesting that administration of MG132 had no effect on memory. Similarly, the group SSZ/MG132 showed levels of freezing comparable with the VEH control group, indicating that UPS inhibition blocked the amnesic effect of sulfasalazine. These results are in agreement with previous observation (Lee et al. 2008), where administration of the UPS inhibitor clasto-lactacystin- $\beta$-lactone into hippocampus did not impair contextual fear memory in mice, but impeded the amnesic effect of the protein synthesis inhibitor anisomycin. The authors also found that the same dose of the UPS inhibitor had no effect on memory during consolidation. In the following experiment we administered MG132 after the training session to compare with those results utilizing the drug clasto-lactacystin$\beta$-lactone. One group of mice was trained with the footshock (SH) and another group was exposed to the training chamber in the absence of footshocks (NS). After the training session, mice received a bilateral intrahippocampal administration of either vehicle or MG132 in the same dose as the previous experiment (NSVEH, SH-VHS, NS-MG132, and SH-MG132). On Day 2, all groups were tested (Fig. 4C). The non-shocked groups displayed significantly lower levels of freezing than the shocked groups, but no effects of the drug were found $\left(F_{(3,36)}=10.45, P<0.05\right.$; NS-VEH vs. SH-VEH: $P<0.05$; NS-MG132 vs. SH-MG132: $P<$ 0.05; SH-VEH vs. SH-MG132: $P$ : NS; NS-VEH vs. NS-MG132: $P$ : NS; data not shown). Next, we used the same experiment design but with a higher dose of MG132, $0.15 \mu \mathrm{g} /$ hemisphere. In contrast to the previous experiment, we found a significantly lower level of freezing in the SH-MG132 group with respect to SHVEH $\left(F_{(3,36)}=16.15, P<0.05\right.$; NS-VEH vs. SH-VEH: $P<0.05$; NS-MG132 vs. SH-MG132: $P$ : NS; SH-VEH vs. SH-MG132: $P<$ 0.05 ; NS-VEH vs. NS-MG132: $P$ : NS) (Fig. 4D), indicating a memory impairment due to UPS inhibition during consolidation. The last two experiments support the interpretation that, in the mouse hippocampus, a higher dose of UPS inhibitor is required to impair memory during consolidation compared with the one needed to block memory labilization after retrieval.

\section{Inhibition of the UPS during reconsolidation blocks the fear memory enhancing effect of the calcineurin inhibitor FK506}

Taking into account the result described above for enhancement of memory during reconsolidation in crabs, we aimed at extending the results to mice. We focused our attention on $\mathrm{Ca}^{2+} / \mathrm{cal}-$ modulin-dependent phosphatase 2B (calcineurin, CaN), an important regulator of the level of protein phosphorylation in the nervous system because it is activated directly by $\mathrm{Ca}^{2+} / \mathrm{cal}-$ modulin signals in synaptic spines. Some studies support its role as a memory constraint in different memory tasks (Baumgärtel et al. 2008; Havekes et al. 2008), and it was found to be involved in memory extinction (Lin et al. 2003; de la Fuente et al. 2011). More recently, we found evidence for the role of $\mathrm{CaN}$ as a negative constrain in contextual fear memory in mice, and that inhibition of CaN by the specific inhibitor FK506 in hippocampus-enhanced memory (V de la Fuente, N Federman, MS Fustiñana, G Zalcman, and A Romano, in prep.). In the following experiment we used FK506 to induce memory enhancement, and to test whether UPS inhibition blocks this memory facilitation during reconsolidation. One group of mice underwent contextual fear conditioning with three footshock presentations, while another three groups 
received a weak training with only one footshock. On Day 2, all groups were re-exposed to the training context for $5 \mathrm{~min}$ and the percentage of freezing was determined; 15 min before re-exposure we bilaterally infused into hippocampus either vehicle, $5 \mu \mathrm{g} /$ hemisphere of FK506, $0.05 \mu \mathrm{g} /$ hemisphere of MG132, or FK506/ MG132 cocktail (FK506/MG132 group). The group that received three trials was injected with vehicle (3SH-VEH group) and was used as a positive control for memory retention at testing. One of the groups trained with one trial also received vehicle (1SH-VEH group), and the other two weakly trained groups were injected with either FK506 (1SH-FK506 group) or FK506/MG132 cocktail (1SH-FK506/MG132 group). On Day 2 only the group of animals that received three trials show high levels of freezing while the three groups that received only one trial on Day 1 elicited significantly low levels of freezing compared with the first group $\left(F_{(3,36)}=6.64, P<0.05 ; 1\right.$ SH-VEH vs. 3 SH-VEH: $P<0.05$; 1SH-VEH vs. 1 SH-FK506: $P$ : NS; 1 SH-VEH vs. 1 SH-FK506/MG132: $P$ : NS; 1SH-FK506506/MG132 vs. 3SH-VEH: $P<0.05$; 1 SHFK506/MG132 vs. 1SH-FK506: $P$ : NS; 1 SH-FK506 vs. 3SH-VEH: $P<0.05$ ) (data not shown). On Day 3, all mice were tested with a second re-exposure of $5 \mathrm{~min}$ (Fig. 5A), and the percentage of freezing was determined (Fig. 5B). As expected, the $3 \mathrm{SH}-\mathrm{VEH}$ group showed high levels of freezing and the $1 \mathrm{SH}-\mathrm{VEH}$ group displayed significantly lower freezing levels. The 1SH-FK506 group displayed high freezing values similar to the $3 \mathrm{SH}-\mathrm{VEH}$ group, but the group injected with the cocktail showed a significantly lower level of freezing $\left(F_{(3,36)}=5.52, P<0.05 ; 1\right.$ SH-VEH vs. 3SH-VEH: $P<$ 0.05 ; 1 SH-VEH vs. 1 SH-FK506: $P<0.05 ; 1$ SH-VEH vs. $1 \mathrm{SH}-$ FK506/MG132: $P$ : NS; 1SH-FK506506/MG132 vs. 3SH-VEH: $P<$ 0.05 ; 1SH-FK506/MG132 vs. 1SH-FK506: $P<0.05$; 1 SH-FK506 vs. 3SH-VEH: $P$ : NS). These results indicate that hippocampal administration of an inhibitor of calcineurin during reconsolidation

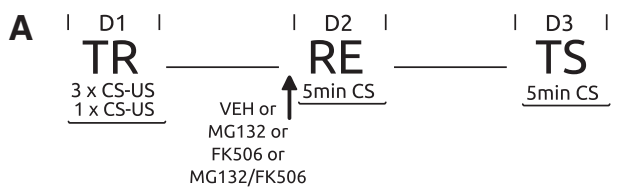

B

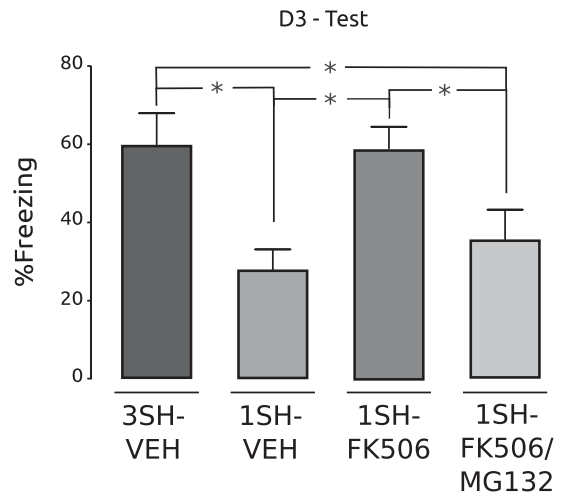

Figure 5. Hippocampal proteasome inhibition impairs the enhancement effect of FK506 during reconsolidation fear conditioning. (A) Experimental protocol. On Day 1 one group of animals were trained with three pairings of CS-US and three groups received only one pairing of CS-US. On Day 2 all groups received a bilateral intra hippocampal injection and $15 \mathrm{~min}$ later were re-exposed to the training context during $5 \mathrm{~min}$. The three trials group and one of one trial received VEH (1E-VEH and 3E-VEH, respectively), another one trial group received FK506 (5 $\mu \mathrm{g} /$ hemisphere) and the other received a cocktail of FK506 and MG132 (FK/MG). On Day 3 the testing session was performed. The arrow indicates the moment of the injection. (B) Testing session. Percentage of freezing \pm SEM on Day $3 ;\left(^{*}\right) P<0.05, n=10$, per group. enhances fear memory. In contrast, coadministration with an inhibitor of UPS blocked this enhancement.

\section{Discussion}

In this work we analyzed the role of the ubiquitin-proteasome system (UPS) in memory consolidation and reconsolidation of two examples of contextual-associative memories, the contextual conditioning of the crab Chasmagnathus and the contextual fear conditioning in mice. The administration of the UPS inhibitor MG132 impaired long-term memory when administered shortly before training, indicating that the UPS is necessary for memory consolidation. This effect, observed in the two models, is in line with the view that negative constrains need to be removed to activate key neural plasticity mechanisms such as the NF-кB pathway of gene expression regulation, as was evidenced previously (Lopez-Salon et al. 2001; Merlo and Romano 2008). The finding that the administration of an inhibitor of UPS in mouse hippocampus induced memory impairment in contextual fear conditioning differs from previous findings of Lee et al. (2008), who found that the UPS inhibitor was unable to induce memory impairment. The different results could be explained by the use of different drugs, clasto-lactacystin- $\beta$-lactone versus MG132. However, it is important to note that we initially found no effect of MG132 on memory consolidation in mice at a dose that was effective during reconsolidation. An increment of the dose was required to observe memory impairment during consolidation. Thus, the lack of effect of clasto-lactacystin- $\beta$-lactone in that report could also be explained by an insufficient dose to impair memory retention.

Conversely to the effect of the UPS inhibitor on memory consolidation, no effect was found during reconsolidation. A simple interpretation of these results is that, in contrast to consolidation, the UPS is no longer required during reconsolidation. However, when the UPS inhibitor is injected in combination with the amnesic drug sulfasalazine, the expected memory impairment was not observed in either memory model. The UPS inhibitor MG132 does not have a direct action on memory reconsolidation but in memory labilization. These findings are in keeping with previous studies using inhibitors of protein synthesis as amnesic agents (Lee et al. 2008, 2012; Jarome et al. 2011; Ren et al. 2013), and support the interpretation that protein degradation is required for memory to become labile after retrieval induced by a brief re-exposure to the training context. However, another interpretation could be that the balance between synthesis and degradation of positive and negative elements governs neural plasticity, as was found in the case of LTP (Fonseca et al. 2006). In that study, it was proposed that protein degradation may be not critical for neural plasticity. Instead, if degradation is inhibited, de novo protein synthesis would no longer be required because preexisting proteins would be enough to sustain the neural plasticity process. Here we used sulfasalazine, which does not interfere directly with the balance between protein synthesis and degradation. Our data extend the previous finding, and support a direct action of the UPS during memory labilization. In addition, our results show that the UPS inhibition not only blocked the amnesic effect of reconsolidationdisrupting drugs, but also blocked the memory enhancing effect of the reconsolidation-enhancing drugs bicuculine and FK506. These findings further support the direct and specific role of the UPS in memory labilization. In other words, labilization process is required for memory modulation after retrieval. If this process is blocked, drugs that enhance or disrupt memory during reconsolidation have no effect.

In the experiments displayed in Figure 4, we found that the dose of MG132 that was effective to block memory labilization 
did not affect consolidation. Instead, a three times higher dose was required to impair memory during consolidation. These data suggest that the requirement and potentially the duration of protein degradation may be different during consolidation than during labilization and a higher dose of UPS inhibitor is required to block such a process.

In the present work we used sulfasalazine, a drug that interferes with an important mechanism of neural plasticity, the IKK/NF-кB pathway. This pathway is considered critical for synaptogenesis (Boersma et al. 2011), and has a key role in different memory models in diverse species (Romano et al. 2006a). Sulfasalazine is a drug that specifically interferes with IKK activity and was used in different memory tasks (Merlo et al. 2002; Boccia et al. 2007; Lubin and Sweatt 2007). In addition, we used here two drugs to produce memory enhancement. One of them, bicuculine, is a competitive antagonist of the GABA receptor type A and was previously used to enhance memory in different taxa and particularly in crabs (Carbo Tano et al. 2009). Alternatively, we administered in mice FK506, a specific inhibitor of CaN. The enhancing effect of FK506 is attributed to the role of CaN as a negative element in consolidation and reconsolidation (Baumgärtel et al. 2008; Havekes et al. 2008; V de la Fuente, N Federman, MS Fustiñana, G Zalcman, and A Romano, in prep.). Moreover, this enhancing effect is specific for reconsolidation, because nonre-exposed animals injected with FK506 did not show memory improvement (V de la Fuente, N Federman, MS Fustiñana, G Zalcman, and A Romano, in prep.). However, this protein phosphatase plays an important role as a positive element in the formation of fear extinction memory (de la Fuente et al. 2011).

The ubiquitin-proteasome mechanism of protein degradation is evolutionarily conserved. The use of two models of associative contextual memory in different phyla allowed us to determine the role of UPS in memory consolidation and reconsolidation. In conclusion, the UPS plays a similar role with similar kinetics although the nervous system organization is completely different in these two species. Our results, together with the previous evidence, support the notion that during consolidation the degradation of proteins which act as negative elements is important for the neural plasticity required for memory storage. During reconsolidation, the degradation of proteins is also critical to allow the process of labilization in which the stored memory becomes susceptible to modification on the basis of new experience.

\section{Materials and Methods}

\section{Animals}

\section{Crabs}

Adult male Chasmagnathus granulatus (recently renamed as Neohelice granulata), Crustacea, Grapsidae, inter-tidal crabs, 2.6$2.9 \mathrm{~cm}$ across the carapace, weight $17 \pm 0.2 \mathrm{~g}(n=60)$, were collected from water $<1 \mathrm{~m}$ deep in the estuarine coasts of San Clemente del Tuyú, Argentina, and transported to the laboratory where they were lodged in plastic tanks $(30 \times 45 \times 20 \mathrm{~cm})$ filled to $0.5 \mathrm{~cm}$ depth with diluted $(12 \%, \mathrm{pH} 7.4-7.6)$ marine water (prepared from Cristalsea Marinemix salts) to a density of 20 crabs per tank. The holding room was maintained on a 12-h light-dark cycle (light on 07:00-19:00 h). Temperature of both holding and experimental rooms was maintained within a range of $22^{\circ} \mathrm{C}-24^{\circ} \mathrm{C}$. Experiments were performed between the third and the tenth day after the animals' arrival. Each crab was used in only one experiment. Experiments were performed in accordance with the local regulations for the care and use of laboratory animals. All efforts were made to minimize animal suffering and to reduce the number of animals used. Furthermore, all the groups included the same number of animals in each experiment, 30 crabs.
Consequently, considering that each experiment included four groups, the number of crabs used was 120 .

\section{Mice}

Balb C male mice, 60-70 d of age, weighing 25-30 g, were used (La Plata University Animal Facilities, La Plata, Argentina). The animals were individually caged and singly housed throughout the experimental procedures, with water and food ad libitum, under a 12-h light/dark cycle (lights on at 8:00 a.m.) at a temperature of $21^{\circ} \mathrm{C}-22^{\circ} \mathrm{C}$. Experiments were performed in accordance with local regulations and the National Institutes of Health (NIH) Guide for the Care and Use of Laboratory Animals (NIH publication 80-23/96). All efforts were made to minimize animal suffering and to reduce the number of animals used.

\section{Experimental devices and behavioral procedures}

\section{Crabs}

The experimental device has been described in detail elsewhere (Lozada et al. 1990). Briefly, the experimental unit was a bowlshaped opaque container surrounded by a steep concave wall 12 $\mathrm{cm}$ high (23-cm top diameter and 9-cm floor diameter). The container was filled with marine water to a depth of $0.5 \mathrm{~cm}$. The crab was placed in the container, which was suspended from an upper wooden framework $(23 \times 23 \times 30 \mathrm{~cm})$ by three strings. A motoroperated screen (US, an opaque rectangular strip of $25.0 \times 7.5$ $\mathrm{cm}$ ) was moved horizontally over the animal from left to right, and vice versa. The screen's movements were cyclical. The screen displacements provoked the escape response of the crab and subsequent container vibrations. Each trial lasted 9 sec and consisted of two successive cycles of movement. Four microphones were attached to the center of the outside base of the container. The microphones recorded the vibrations that were produced by the animal's response. These signals were amplified, integrated during the entire trial $(9 \mathrm{sec})$, and translated into arbitrary numerical units ranging from zero to 8000 . During the experiment, the crabs were illuminated using a 5-W bulb placed either above or below the container (Perez-Cuesta et al. 2007). A computer was used to program the trial sequences, trial illumination, trial duration, and inter-trial intervals and to monitor the experimental events. The experimental room contained 40 experimental devices that were separated from each other by partitions.

The training and other treatment sessions were preceded by $10 \mathrm{~min}$ of adaptation to the experimental device, which was illuminated from below throughout. A standard CSM training session consisted of 15 US presentations without light shift (above illumination) with an inter-trial interval (ITI) of $171 \mathrm{sec}$. A standard contextual Pavlovian conditioning (CPC) training session consisted of 15 trials. Each trial lasted 27 sec with above illumination (CS), and the US was presented during the last 9 sec. The ITI between US presentations was $171 \mathrm{sec}$, as in the standard CSM protocol, but the ITI between CS presentations was $153 \mathrm{sec}$. During the ITI, the experimental unit was illuminated from below, which provoked a virtual change in the environmental features. The untrained animals were kept in the experimental unit during the entire training session. These animals were not presented with the US, but were presented with the same pattern of light shift. Immediately after each session, the crabs were moved from the experimental unit to individual resting containers, which were plastic boxes that were filled with water to a depth of $0.5 \mathrm{~cm}$. The resting containers were kept inside dimly lit drawers. One trial of the US was presented before the training to measure the responsiveness of each animal. No differences were found between groups in this pre-training trial for any of the experiments (Fustiñana et al. 2013).

\section{Mice}

The conditioning chamber (context A) was made of transparent acrylic $(24.5 \times 24.5 \times 42 \mathrm{~cm})$ in a wooden box with a clear front 
lid. The floor of the chamber consisted of parallel stainless-steel grid bars, each measuring $0.3 \mathrm{~mm}$ in diameter and spaced 0.8 $\mathrm{mm}$ apart. The grid was connected to a device to deliver the footshocks and tone presentations. Before training, the animals were handled once a day for $2 \mathrm{~d}$. Training consisted of placing the mouse in the chamber (context A) and allowing a 2 min acclimatization period. After this period, the mice received three trials (with an ITI of $1 \mathrm{~min}$ ) of a tone presentation $(10 \mathrm{sec}, 80 \mathrm{~dB})$, which coterminated with a footshock $(0.6 \mathrm{~mA}, 1 \mathrm{sec})$. The mice remained in the chamber for an additional minute and were returned to their home cages. Contextual fear conditioning during the test session was evaluated 2,8 , and $15 \mathrm{~d}$ after training by placing the mice in the training environment for $5 \mathrm{~min}$ in the absence of the footshock and the tone. In all experiments, the animals were also tested to the tone (cued fear conditioning) $1 \mathrm{~d}$ after the first contextual test, Day 4 . This test was performed by presenting the same tone used in training session, but in a modified chamber (context B). Most of the contextual cues present in the training context were changed (white floor, semicircular green walls, vanilla odor, different chamber and room light intensity, and the absence of background noise). The tone was presented for $4 \mathrm{~min}$ after a baseline period of $2 \mathrm{~min}$ to evaluate pre-tone freezing. Each test was videotaped to calculate freezing.

Memory was assessed and expressed as the percentage of time that the mice spent freezing, which is commonly used as an index of fear in mice. Freezing was defined as the absence of all movements except those related to breathing. Freezing was scored according to an instantaneous time-sampling procedure in which each animal was observed every $5 \mathrm{sec}$ in a $300 \mathrm{sec}$ testing period in the case of contextual test (60 measures).

\section{Surgery and injections}

\section{Crabs}

Fifty microliters of the vehicle (VEH) or drug solution was injected through the right side of the dorsal cephalothoracic-abdominal membrane by a syringe that was fitted with a sleeve to control the depth of penetration to $4 \mathrm{~mm}$, thus ensuring that the injected solution was released into the pericardial sac.

\section{Mice}

Mice were implanted under deep anesthesia (ketamine and xylazine) with a 23-gauge guide cannulae $1 \mathrm{~mm}$ dorsally to the dorsal hippocampus, at coordinates of anterior, -1.9 ; lateral, \pm 1.2 ; and ventral, 1.2, in accordance with the atlas of Paxinos and Franklin (2001). Guide cannulae were fixed to the skull with dental acrylic. Experiments were performed after animal recovery and injections were administered immediately before or after context reexposure (see Results) without anesthesia. The injection device consisted of a 30-gauge cannula connected to a $5 \mu \mathrm{L}$ Hamilton syringe with tubing. Initially, the infusion device was filled with distilled water and a small air bubble was sucked into the injection cannula, followed by the injection solution. The air bubble allowed for visual inspection of the injection progress. The injection cannula was inserted into the guide cannula with its tip extending beyond the guide by $1 \mathrm{~mm}$ to reach the dorsal hippocampus. The injections were administered during $30 \mathrm{sec}$ and operated by hand. The injection cannula was removed after 60 sec to avoid reflux and to allow the diffusion of drugs. The volume of each intrahippocampal infusion was $0.5 \mu \mathrm{L} /$ hemisphere. Different injection devices were used for drug and vehicle. After behavioral procedures, the animals were injected with black ink and were decapitated. The brains were placed in $4 \%$ paraformaldehyde for $1 \mathrm{~d}$ followed by $30 \%$ sucrose for an additional $24 \mathrm{~h}$. To verify cannulae placement, frozen brains were sliced using a cryostat and analyzed with a magnifying glass. The deepest position of the needle was superimposed on serial coronal maps. Only data from animals with cannulae located in the intended sites were included in the analysis.

\section{Drugs}

The following drugs were used: sulfasalazine (SSZ) [2,4-hydroxy((4-((2-pyridinylamino)-sulphonyl)-phenyl)-azo)-benzoic acid] (Sigma-Aldrich, St. Louis, MO, USA), which is an NF-кB inhibitor, was freshly dissolved at a final dose of $1.2 \mu \mathrm{g} / \mathrm{g}$ of animal $(5 \mathrm{mM})$ in crab (Merlo et al. 2002) and $0.5 \mu \mathrm{g}$ per hemisphere $(2.5 \mathrm{mM})$ in mice (Boccia et al. 2007). The proteasome inhibitor MG132 (N-CBZ-LEU-LEU-LEU-AL) (Sigma-Aldrich) was injected at a final dose of $2.38 \mu \mathrm{g} /$ animal $(750 \mu \mathrm{M})$ in crab and $0.05 \mu \mathrm{g} /$ hemisphere and $0.15 \mu \mathrm{g} /$ hemisphere in mice. In crabs we used (+)-bicuculline (BIC) (Fluka analytical), which is a competitive antagonist of GABAA receptor (Carbo Tano et al. 2009), was administered at a final dose of $2.69 \mu \mathrm{g} / \mathrm{g}$ of animal and MK801 [(+)-5-methyl10,11-dihydro-5 $H$-ibenzo[ $a, d]$ cyclohepten-5,10-imine] (SigmaAldrich) at a final dose of $0.6 \mu \mathrm{g} / \mathrm{g}$ of animal. In mice we also used $(3 S, 4 R, 5 S, 8 R, 9 E, 12 S, 14 S, 15 R, 16 S, 18 R, 19 R, 26 a S)-5,6,8$, $11,12,13,14,15,16,17,18,19,24,25,26,26 a$-hexadecahydro-5,19-dihydroxy-3-[(1E)-2-[(1R,3R,4R)-4-hydroxy-3-methoxycyclohexyl]1-methylethenyl]-14,16-dimethoxy-4,10,12,18-tetramethyl-8-(2propen-1-yl)-15,19-epoxy-3H-pyrido[2,1-c][1,4] oxaazacyclotricosine-1,7,20,21(4H,23H)-tetrone, monohydrate [FK-506 (FK)] (Sigma-Aldrich), an inhibitor of the calcineurin phosphatase (CaN) administered at a final dose of $5 \mu \mathrm{g} /$ hemisphere $(10 \mu \mathrm{g} / \mu \mathrm{L})$ (V de la Fuente, N Federman, MS Fustiñana, G Zalcman, and A Romano, in prep.). All the drugs were diluted in dimethyl sulfoxide (DMSO) which was used as VEH.

\section{Data analysis and drug effect evaluation}

In the crab CPC, retention of the learning acquired during training was considered to have occurred when a significantly lower level of response in the testing session was found for the trained group compared with its control group (i.e., both groups were injected with the same solution or treated with the same behavioral manipulation). The rationale for this criterion is based on the previous experiments performed in our laboratory. In these experiments, a significant difference ( $t$-test, $\alpha=0.05$ ) between the trained (TR) and untrained (UT) groups was invariably identified at testing sessions that took place $24 \mathrm{~h}$ or more after training. The experiments demonstrating this difference included 15 or more training trials with 171-sec inter-trial intervels. Accordingly, for the current experiment, a significant difference was predicted at testing between the UT and TR groups. Therefore, throughout the current paper, the results from the behavioral study were analyzed using a priori planned comparisons via a weighted means ANOVA with $\alpha$ (per comparison error rate) $=0.05$, according to the standard method (Howell 1987). A lack of difference between the UT and TR groups was assumed to indicate a lack of memory retention. The statistical analysis of the test data included a set of three a priori planned comparisons, namely each pair of UTTR groups and the comparison between the two UT groups, using planned comparisons of least squares means with $\alpha$ (per comparison error rate) $<0.05$ (Rosenthal and Rosnow 1985; Howell 1987). A comparison between the control groups that received different treatments was necessary to determine the possible drug or behavioral manipulation side effects that may have affected the response level at testing in a manner that was unrelated to training experience. In all the experiments of the current paper, no differences were found in this comparison. For each experiment, a prediction was made based on the experimental design. In general, we could predict that, in the first comparison, a difference between the UT and TR groups was expected due to the reduction in the response level that was induced by training in the latter group (e.g., this group received a strong training protocol without any other treatment). Conversely, in the second comparison, if the drug impaired retention, then no differences were expected between the UT-TR pair. Finally, as long as the behavioral manipulation or the drug did not affect the level of response at testing, then no difference was expected in the comparison between control groups. All of the values were represented as the normalized mean \pm the standard error with respect to the main control group (100\%, e.g., CPC, P, or VEH). 
In mice, behavioral data were analyzed by two-way ANOVA, followed by Newman-Keuls multiple comparisons post hoc test, comparing the values of the percentages of freezing.

\section{Acknowledgments}

We thank Johannes J. Letzkus for revision of the manuscript and language correction, and Angel Vidal for technical assistance. This research was supported by FONCYT PICT 2049, FONCYT PICT 1482, Argentina, UBACYT X198, Universidad de Buenos Aires, and PIP 5466, CONICET, Argentina.

\section{References}

Alberini CM. 2009. Transcription factors in long-term memory and synaptic plasticity. Physiol Rev 89: 121-145.

Amano H, Maruyama IN. 2011. Aversive olfactory learning and associative long-term memory in Caenorhabditis elegans. Learn Mem 18: 654-665.

Artinian J, McGauran A-MT, De Jaeger X, Mouledous L, Frances B, Roullet P. 2008. Protein degradation, as with protein synthesis, is required during not only long-term spatial memory consolidation but also reconsolidation. Eur J Neurosci 27: 3009-3019.

Baumgärtel K, Genoux D, Welzl H, Tweedie-Cullen RY, Koshibu K, Livingstone-Zatchej M, Mamie C, Mansuy IM. 2008. Control of the establishment of aversive memory by calcineurin and Zif268. Nat Neurosci 11: 572-578.

Boccia M, Freudenthal R, Blake M, de la Fuente V, Acosta G, Baratti C, Romano A. 2007. Activation of hippocampal nuclear factor-к B by retrieval is required for memory reconsolidation. J Neurosci 27: 13436-13445.

Boersma MCH, Dresselhaus EC, De Biase LM, Mihalas AB, Bergles DE, Meffert MK. 2011. A requirement for nuclear factor-кB in developmental and plasticity-associated synaptogenesis. J Neurosci 31: 5414-5425.

Carbo Tano M, Molina VA, Maldonado H, Pedreira ME. 2009. Memory consolidation and reconsolidation in an invertebrate model: the role of the GABAergic system. Neuroscience 158: 387-401.

Chain DG, Schwartz JH, Hegde AN. 1999. Ubiquitin-mediated proteolysis in learning and memory. Mol Neurobiol 20: 125-142.

Chapouthier G, Venault P. 2002. GABA-A receptor complex and memory processes. Curr Top Med Chem 8: 841-851.

Colledge M, Snyder EM, Crozier RA, Soderling JA, Jin Y, Langeberg LK, Lu H, Bear MF, Scott JD. 2003. Ubiquitination regulates PSD-95 degradation and AMPA receptor surface expression. Neuron 40: 595-607.

de la Fuente V, Freudenthal R, Romano A. 2011. Reconsolidation or extinction: transcription factor switch in the determination of memory course after retrieval. J Neurosci 31: 5562-5573.

Delorenzi A, Maldonado H. 1999. Memory enhancement by the angiotensinergic system in the crab Chasmagnathus is mediated by endogenous angiotensin II. Neurosci Lett 266: 1-4.

Dudai Y. 2006. Reconsolidation: the advantage of being refocused. Curr Opin Neurobiol 16: 174-178.

Ehlers MD. 2003. Activity level controls postsynaptic composition and signaling via the ubiquitin-proteasome system. Nat Neurosci 6: 231-242.

Fonseca R, Vabulas RM, Hartl FU, Bonhoeffer T, Nägerl UV. 2006. A balance of protein synthesis and proteasome-dependent degradation determines the maintenance of LTP. Neuron 52: 239-245.

Freudenthal R, Boccia MM, Acosta GB, Blake MG, Merlo E, Baratti CM, Romano A. 2005. NF-кB transcription factor is required for inhibitory avoidance long-term memory in mice. Eur J Neurosci 21: 2845-2852.

Fustiñana MS, Carbó Tano M, Romano A, Pedreira ME. 2013. Contextual Pavlovian conditioning in the crab Chasmagnathus. Anim Cogn 16: 255-272.

Gutiérrez H, Gutiérrez R, Silva-Gandarias R, Estrada J, Miranda MI, Bermúdez-Rattoni F. 1999. Differential effects of 192IgG-saporin and NMDA-induced lesions into the basal forebrain on cholinergic activity and taste aversion memory formation. Brain Res 834: 136-141.

Havekes R, Nijholt IM, Visser AKD, Eisel ULM, Van der Zee EA. 2008. Transgenic inhibition of neuronal calcineurin activity in the forebrain facilitates fear conditioning, but inhibits the extinction of contextual fear memories. Neurobiol Learn Mem 89: 595-598.

Hepp Y, Tano MC, Pedreira ME, Freudenthal RAM. 2013. NMDA-like receptors in the nervous system of the crab Neohelice granulata: a neuroanatomical description. J Comp Neurol 521: 2279-2297.

Hou L, Antion MD, Hu D, Spencer CM, Paylor R, Klann E. 2006. Dynamic translational and proteasomal regulation of fragile $\mathrm{X}$ mental retardation protein controls mGluR-dependent long-term depression. Neuron 51: 441-454.

Howell DC. 1987. Statistical methods for psychology. 2nd ed. Duxbury Press, Boston.
Jarome TJ, Werner CT, Kwapis JL, Helmstetter FJ. 2011. Activity dependent protein degradation is critical for the formation and stability of fear memory in the amygdala. PLoS One 6: e24349.

Kano T, Brockie PJ, Sassa T, Fujimoto H, Kawahara Y, Iino Y, Mellem JE, Madsen DM, Hosono R, Maricq AV. 2008. Memory in Caenorhabditis elegans is mediated by NMDA-type ionotropic glutamate receptors. Curr Biol 18: 1010-1015.

Karpova A, Mikhaylova M, Thomas U, Knöpfel T, Behnisch T. 2006. Involvement of protein synthesis and degradation in long-term potentiation of Schaffer collateral CA1 synapses. J Neurosci 26: 4949-4955.

Kida S, Josselyn SA, Pena de Ortiz S, Kogan JH, Chevere I, Masushige S, Silva AJ. 2002. CREB required for the stability of new and reactivated fear memories. Nat Neurosci 5: 348-355.

Lee SH, Choi JH, Lee N, Lee HR, Kim JI, Yu NK, Choi SL, Kim H, Kaang BK. 2008. Synaptic protein degradation underlies destabilization of retrieved fear memory. Science 319: 1253-1256.

Lee S-H, Kwak C, Shim J, Kim J-E, Choi S-L, Kim HF, Jang D-J, Lee J-A, Lee K, Lee C-H, et al. 2012. A cellular model of memory reconsolidation involves reactivation-induced destabilization and restabilization at the sensorimotor synapse in Aplysia. Proc Natl Acad Sci 109: 14200-14205.

Lin XY, Glanzman DL. 1994. Hebbian induction of long-term potentiation of Aplysia sensorimotor synapses: partial requirement for activation of an NMDA-related receptor. Proc Biol Sci 255: 215-221.

Lin C-H, Yeh S-H, Leu T-H, Chang W-C, Wang S-T, Gean P-W. 2003. Identification of calcineurin as a key signal in the extinction of fear memory. J Neurosci 23: 1574-1579.

Lopez-Salon M, Alonso M, Vianna MR, Viola H, Mello e Souza T, Izquierdo I, Pasquini JM, Medina JH. 2001. The ubiquitin-proteasome cascade is required for mammalian long-term memory formation. Eur J Neurosci 14: 1820-1826.

Lozada M, Romano A, Maldonado H. 1990. Long-term habituation to a danger stimulus in the crab Chasmagnathus granulatus. Physiol Behav 47: $35-41$.

Lubin FD, Sweatt JD. 2007. The IкB kinase regulates chromatin structure during reconsolidation of conditioned fear memories. Neuron 55: 942-957.

Mactutus C, Riccio D, Ferek J. 1979. Retrograde amnesia for old (reactivated) memory: some anomalous characteristics. Science 204: 1319-1320.

Meffert MK, Baltimore D. 2005. Physiological functions for brain NF-кB. Trends Neurosci 28: 37-43.

Merlo E, Romano A. 2007. Long-term memory consolidation depends on proteasome activity in the crab Chasmagnathus. Neuroscience 147: $46-52$.

Merlo E, Romano A. 2008. Memory extinction entails the inhibition of the transcription factor NF-кB. PLoS One 3: e3687.

Merlo E, Freudenthal R, Romano A. 2002. The IкB kinase inhibitor sulfasalazine impairs long-term memory in the crab Chasmagnathus. Neuroscience 112: 161-172.

Merlo E, Freudenthal R, Maldonado H, Romano A. 2005. Activation of the transcription factor NF-кB by retrieval is required for long-term memory reconsolidation. Learn Mem 12: 23-29.

Misanin JR, Miller RR, Lewis DJ. 1968. Retrograde amnesia produced by electroconvulsive shock after reactivation of a consolidated memory trace. Science 160: $554-555$.

Miserendino MJ, Sananes CB, Melia KR, Davis M. 1990. Blocking of acquisition but not expression of conditioned fear-potentiated startle by NMDA antagonists in the amygdala. Nature 345: $716-718$.

Morris RG, Anderson E, Lynch GS, Baudry M. 1986. Selective impairment of learning and blockade of long-term potentiation by an $N$-methyl-D-aspartate receptor antagonist, AP5. Nature 319: $774-776$.

Müller GE, Pilzecker A. 1900. Experimentelle Beiträge zur Lehre vom Gedächtnis. Z Psychol Ergänzungsband 1: 1-300.

Müssig L, Richlitzki A, Rössler R, Eisenhardt D, Menzel R, Leboulle G. 2010. Acute disruption of the NMDA receptor subunit NR1 in the honeybee brain selectively impairs memory formation. J Neurosci 30: $7817-7825$.

Nader K, Schafe GE, LeDoux JE. 2000. The labile nature of consolidation theory. Nat Rev Neurosci 1: 216-219.

Paxinos G, Franklin KBJ. 2001. The mouse brain in stereotaxic coordinates, 2nd ed. Academic Press, San Diego, CA.

Pedreira ME, Maldonado H. 2003. Protein synthesis subserves reconsolidation or extinction depending on reminder duration. Neuron 38: $863-869$.

Pedreira ME, Pérez-Cuesta LM, Maldonado H. 2002. Reactivation and reconsolidation of long-term memory in the crab Chasmagnathus: Protein synthesis requirement and mediation by NMDA-type glutamatergic receptors. J Neurosci 22: 8305-8311. 
Pérez-Cuesta LM, Maldonado H. 2009. Memory reconsolidation and extinction in the crab: mutual exclusion or coexistence? Learn Mem 16: $714-721$.

Perez-Cuesta LM, Hepp Y, Pedreira ME, Maldonado H. 2007. Memory is not extinguished along with CS presentation but within a few seconds after CS-offset. Learn Mem 14: 101-108.

Ren Z-Y, Liu M-M, Xue Y-X, Ding Z-B, Xue L-F, Zhai S-D, Lu L. 2013. A critical role for protein degradation in the nucleus accumbens core in cocaine reward memory. Neuropsychopharmacology 38: $778-790$.

Rickard NS, Poot AC, Gibbs ME, Ng KT. 1994. Both non-NMDA and NMDA glutamate receptors are necessary for memory consolidation in the dayold chick. Behav Neural Biol 62: 33-40.

Roberts AC, Glanzman DL. 2003. Learning in Aplysia: looking at synaptic plasticity from both sides. Trends Neurosci 26: 662-670.

Roff M, Thompson J, Rodriguez MS, Jacque JM, Baleux F, ArenzanaSeisdedos F, Hay RT. 1996. Role of ІкB $\alpha$ ubiquitination in signal-induced activation of NFкB in vivo. J Biol Chem 271: $7844-7850$

Romano A, Freudenthal R, Merlo E, Routtenberg A. 2006a. Evolutionarilyconserved role of the NF- $\mathrm{B}$ transcription factor in neural plasticity and memory. Eur J Neurosci 24: 1507-1516.

Romano A, Locatelli F, Freudenthal R, Merlo E, Feld M, Ariel P, Lemos D, Federman N, Fustiñana MS. 2006b. Lessons from a crab: molecular mechanisms in different memory phases of Chasmagnathus. Biol Bull 210: $280-288$.

Rosenegger D, Lukowiak K. 2010. The participation of NMDA receptors, $\mathrm{PKC}$, and MAPK in the formation of memory following operant conditioning in Lymnaea. Mol Brain 3: 24.

Rosenthal R, Rosnow RL. 1985. Contrast analysis: Focused comparisons in the analysis of variance. Cambridge University Press, New York.

Sara SJ. 2000. Retrieval and reconsolidation: toward a neurobiology of remembering. Learn Mem 7: 73-84.
Sekiguchi T, Yamada A, Suzuki H. 1997. Reactivation-dependent changes in memory states in the terrestrial slug Limax flavus. Learn Mem 4: $356-364$.

Si A, Helliwell P, Maleszka R. 2004. Effects of NMDA receptor antagonists on olfactory learning and memory in the honeybee (Apis mellifera). Pharmacol Biochem Behav 77: 191-197.

Si J, Yang J, Xue L, Yang C, Luo Y, Shi H, Lu L. 2012. Activation of NF-кB in basolateral amygdala is required for memory reconsolidation in auditory fear conditioning. PLoS One 7: e43973.

Tan S, Kirk RC, Abraham WC, McNaughton N. 1989. Effects of the NMDA antagonists CPP and MK-801 on delayed conditional discrimination. Psychopharmacology (Berl) 98: 556-560.

Troncoso J, Maldonado H. 2002. Two related forms of memory in the crab Chasmagnathus are differentially affected by NMDA receptor antagonists. Pharmacol Biochem Behav 72: 251-265.

Wahl C, Liptay S, Adler G, Schmid RM. 1998. Sulfasalazine: a potent and specific inhibitor of nuclear factor к B. J Clin Invest 101: 1163-1174.

Weber CK, Liptay S, Wirth T, Adler G, Schmid RM. 2000. Suppression of NF$\kappa \mathrm{B}$ activity by sulfasalazine is mediated by direct inhibition of IкB kinases $\alpha$ and $\beta$. Gastroenterology 119: 1209-1218.

Weldon DA, Fedorcik GG, LoRusso CM, Tiburzi MJ, Lenoci JM. 1997. Olfactory conditioning impairment following posttraining NMDA receptor blockade in neonatal rats. Neurobiol Learn Mem 67: 34-42.

Wu C-L, Xia S, Fu T-F, Wang H, Chen Y-H, Leong D, Chiang A-S, Tully T. 2007. Specific requirement of NMDA receptors for long-term memory consolidation in Drosophila ellipsoid body. Nat Neurosci 10: $1578-1586$.

Xia S, Miyashita T, Fu T-F, Lin W-Y, Wu C-L, Pyzocha L, Lin I-R, Saitoe M, Tully T, Chiang A-S. 2005. NMDA receptors mediate olfactory learning and memory in Drosophila. Curr Biol 15: 603-615.

Received June 5, 2014; accepted in revised form June 27, 2014. 
Learning \& Memory 21: 478-487 (2014)

Protein degradation by ubiquitin-proteasome system in formation and labilization of contextual conditioning memory

María Sol Fustiñana, Verónica de la Fuente, Noel Federman, Ramiro Freudenthal, and Arturo Romano

In the original version of this article, Verónica de la Fuente was accidentally removed from the list of authors during the composition process. The publisher apologizes for this omission, which has been corrected in the current version online.

Learning \& Memory 21: 534-542 (2014)

Molecular mechanisms underlying formation of long-term reward memories and extinction memories in the honeybee (Apis mellifera)

Dorothea Eisenhardt

The last sentence at the bottom of page 535, column 1, should read: "The honeybee genome project revealed a plethora of honeybee proteins homologous to vertebrate neuronal proteins (Honeybee Genome Sequencing Consortium 2006)." The publisher apologizes for the erroneous typo, which has been corrected in the current version online. 


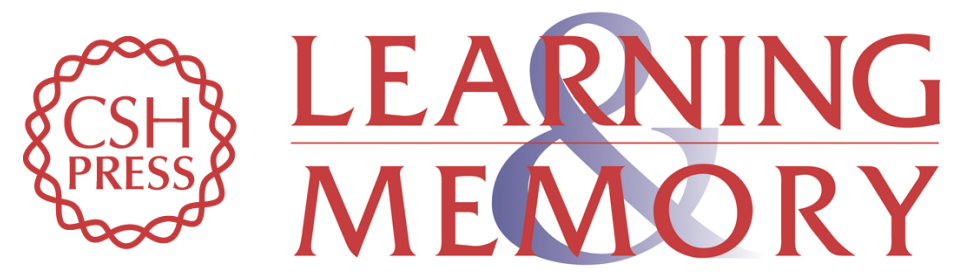

\title{
Protein degradation by ubiquitin-proteasome system in formation and labilization of contextual conditioning memory
}

María Sol Fustiñana, Verónica de la Fuente, Noel Federman, et al.

Learn. Mem. 2014, 21:

Access the most recent version at doi:10.1101/Im.035998.114

\begin{abstract}
Related Content Protein degradation by ubiquitin-proteasome system in formation and labilization of contextual conditioning memory

María Sol Fustiñana, Verónica de la Fuente, Noel Federman, et al.

Learn. Mem. November , 2014 21: 646.1

References This article cites 66 articles, 18 of which can be accessed free at:

http://learnmem.cshlp.org/content/21/9/478.full.html\#ref-list-1

Articles cited in:

http://learnmem.cshlp.org/content/21/9/478.full.html\#related-urls

Creative This article is distributed exclusively by Cold Spring Harbor Laboratory Press for the Commons first 12 months after the full-issue publication date (see

License http://learnmem.cshlp.org/site/misc/terms.xhtml). After 12 months, it is available under a Creative Commons License (Attribution-NonCommercial 4.0 International), as described at http://creativecommons.org/licenses/by-nc/4.0/.

Email Alerting Receive free email alerts when new articles cite this article - sign up in the box at the Service top right corner of the article or click here.
\end{abstract}

